\title{
A IMPLEMENTAÇÃO DO PLANO TERRITORIAL DE DESENVOLVIMENTO RURAL SUSTENTÁVEL E DO PROGRAMA TERRITÓRIOS DA CIDADANIA NO ESTADO DE RONDÔNIA
}

\author{
Oleides Francisca de Oliveira* \\ Gleimíria Batista da Costa ** \\ Heleniza Ávila Campos **** \\ Jeoval Batista da Silva *****
}

\begin{abstract}
Resumo
Este artigo aborda as intervenções voltadas ao desenvolvimento territorial no Brasil, pelas políticas de desenvolvimento local/rural e mais especificamente pelo Plano Territorial de Desenvolvimento Rural Sustentável (PTDRS) no Estado de Rondônia. Essa política, implantada no início do Governo Lula (2003), centrou-se em dois recortes territoriais em Rondônia: o Central e o Madeira Mamoré, à medida que foram os dois primeiros a participarem do Plano no estado. $\mathrm{O}$ artigo está estruturado em dois momentos: no primeiro, analisam-se os principais resultados do levantamento referente ao fluxo migratório para a ocupação e desenvolvimento do Estado de Rondônia entre 1950 e 2010; no segundo, reflete-se sobre a implantação do Programa Territórios da Cidadania nos dois recortes territoriais de Rondônia. Utilizam-se os procedimentos de análise de dados estatísticos disponíveis em órgãos oficiais e pesquisa documental - disponibilizada pelo Ministério de Desenvolvimento Agrário (MDA) - acerca de conceitos e avaliações de políticas públicas rurais no País. Parte-se da hipótese de que, no Brasil, a condição centralizada das políticas públicas rurais implementadas pelo governo federal pouco consideram as características regionais diferenciadas espacial, social e economicamente.
\end{abstract}

Palavras-chave: Território. Desenvolvimento Rural. Políticas Públicas. Região Norte do Brasil.

\footnotetext{
* Doutora em Desenvolvimento Regional pela Universidade de Santa Cruz do Sul - UNISC/RS. Docente do Curso de Ciências Contábeis da Universidade Federal de Rondônia - UNIR/RO. E-mail: oleides@yahoo.com.br. ** Doutora em Desenvolvimento Regional pela Universidade de Santa Cruz do Sul - UNISC/RS. Docente do Curso de Ciências Contábeis da Universidade Federal de Rondônia - UNIR/RO. E-mail: gleimiria@unir.br.

*** Doutora em Geografia pela Universidade Federal do Rio de Janeiro - UFRJ/RJ. Docente do curso de Urbanismo da Universidade do Rio Grande do Sul - UFRGS. E-mail: heleniza.campos@yahoo.com.br.

***** Auditor da Prefeitura Municipal de Porto Velho/RO. Coordenador do Programa Território da Cidadania Madeira Mamoré/RO.E-mail: jeovalbs@hotmail.com.
} 


\section{Introdução}

As políticas rurais no Brasil tradicionalmente têm favorecido as grandes propriedades voltadas à produção extensiva agropecuária, com investimento em tecnologia com renovação de máquinas e equipamentos. No entanto, há uma forte presença das pequenas propriedades, estando estas vinculadas a uma prática de produção ligadas as suas características regionais.

Outro aspecto importante é que as políticas agrárias implementadas pelo Governo Federal têm se caracterizado historicamente pela centralização das decisões e parecem tratar as diferentes realidades territoriais nacionais como um espaço homogêneo, cujas particularidades regionais tão distintas são desconsideradas, e acabam por sujeitar a matriz social e produtiva quase exclusivamente aos interesses homogeneizantes. Estas políticas muito centralizadas na definição de estratégias e na gestão acabam por ampliar as desigualdades regionais já existentes na sua implementação. Por serem pouco sensíveis às particularidades locais e ao enfoque sistêmico, acabam por sujeitar a matriz social e produtiva exclusivamente aos interesses nacionais (ADIB, 2005).

As políticas públicas brasileiras têm tradicionalmente concentrado suas estratégias de investimentos em regiões de ocupação muito consolidada, em que o adensamento populacional e a concentração de renda se fazem presentes. Tais práticas limitam o reconhecimento da importância de grupos sociais tradicionais em processos de desenvolvimento, tais como a população ribeirinha, os seringueiros, os quilombolas, os indígenas.

No estado de Rondônia, situado na Região Norte do Brasil, estas disparidades entre os conflitos regionais e o foco do planejamento regional ficam evidentes. $\mathrm{O}$ processo de ocupação territorial ocorreu mais intensamente a partir da década de 1970, momento de grande incentivo pelo governo federal a outras regiões do País com a finalidade de apropriação da Região Norte através de grandes projetos de ocupação, tais como o Programa de Desenvolvimento da Região Noroeste do Brasil POLONOROESTE (1981) - e Plano Agropecuário e Florestal de Rondônia - PLANAFLORO (1986) -, do governo estadual.

Essa ocupação do estado no período de 1970 a 1980 ocorreu em ritmo acelerado, caracterizado por interesses particulares de grupos ruralistas e grandes proprietários de terra, sem a preocupação de sustentabilidade em longo prazo. Nas décadas 
seguintes, ou seja, entre os anos 1980 e 1990, outros planos foram propostos pelo governo federal como política de implementação dessa ocupação com ênfase na concepção de desenvolvimento sustentável em âmbito nacional.

A ação mais recente do governo federal para o desenvolvimento rural é o Plano Territorial de Desenvolvimento Rural Sustentável (PTDRS), instituído em 2003, com o objetivo de tratar especificamente do desenvolvimento territorial e rural. Essa política de desenvolvimento territorial é de iniciativa do Ministério do Desenvolvimento Agrário (MDA) em parceria com estados, municípios e organizações da sociedade civil. As dificuldades encontradas nacionalmente para estabelecer metas exclusivamente para o meio rural em razão das disparidades sociais e econômicas existentes suscitaram novas estratégias políticas que resultaram no Programa Territórios da Cidadania (PTC), criado em 2008.

Diante da grande extensão de área nacional e diferenciação das características regionais, este artigo busca apontar para a necessidade de articulação entre políticas públicas federais e regionais.Visa discutir as intervenções voltadas ao desenvolvimento territorial no Brasil, pelas políticas de desenvolvimento local/rural e pelo PTDRS no estado de Rondônia, na Região Norte do Brasil.

A estrutura aqui proposta compõe-se de três partes: na primeira, é realizada uma caracterização dos aspectos territoriais, demográficos e econômicos do Estado de Rondônia; a segunda discute os conceitos de território rural e sustentabilidade, considerando dois aspectos fundamentais na realidade brasileira: a implementação e gestão dos planos de desenvolvimento para Rondônia, em particular o PTDRS e o Programa Territórios da Cidadania na Região Norte, com destaque para a realidade do estado de Rondônia; por fim, são delineadas as considerações finais sobre o tema.

\section{Caracterização do estado de Rondônia}

O estado de Rondônia originou-se do desmembramento dos estados do Amazonas e Mato Grosso, administrado diretamente pela União, através do Ministério do Interior e Justiça. O Decreto Lei n. 5.832, de 21 de setembro de 1943, que dispõe sobre a administração e divisão política dos territórios federais, subordinou o novo estado à administração direta da União. Em 
17 de fevereiro de 1956, passou a ser território de Rondônia, sob a Lei n. 21.731, em homenagem ao Marechal Cândido Mariano da Silva Rondon. Em 22 de dezembro de 1981, sob a Lei Complementar n. 41, passou a estado com o mesmo nome, "Rondônia". O estado está localizado na Amazônia Legal e na Região Norte do Brasil, tem como limites os estados do Mato Grosso a leste, Amazonas ao norte, Acre a oeste e a República da Bolívia a oeste e sul (LIMA, 1997).

Rondônia é um dos sete estados que compõem a Região Norte brasileira: Acre, Amapá, Amazonas, Pará, Rondônia, Roraima e Tocantins. Essa região possui uma área de $3.659 .637,9 \mathrm{~km}^{2}$, que corresponde a $42,27 \%$ do território brasileiro, sendo a maior região brasileira em superfície. $\mathrm{O}$ estado de Rondônia é uma das 27 unidades federativas do Brasil, possui $237.590,547.12 \mathrm{~km}^{2}$ de extensão, representando 6,19\% da área total da Região Norte e 2,80\% da área total do Brasil; é composto por 52 municípios, tendo como capital Porto Velho, com 1.503.928 habitantes; é o $3^{\circ}$ estado mais populoso e o mais denso da Região Norte, sendo o $23^{\circ}$ mais populoso do Brasil. Na estimativa para 2009 do Instituto Brasileiro de Geografia Estatística (IBGE), Porto Velho, a capital do estado, conta com uma população aproximada de 382.829 habitantes - é a maior cidade do estado e $4^{\mathrm{a}}$ maior cidade da Região Norte do Brasil, ficando atrás de Manaus (AM), Belém (PA) e Ananindeua (PA) (IBGE, 2010).

Diante do grande fluxo migratório nas últimas três décadas para Rondônia, o governo federal buscou realizar projetos com o objetivo de organizar e ordenar a ocupação e o desenvolvimento do território. Dentre os principais planos voltados a esta região, destacam-se o POLONOROESTE e o PLANAFLORO. É importante salientar que se destaca na composição econômica de Rondônia a atividade extrativista, vegetal e mineral, mais especificamente a exploração da madeira nativa. $\mathrm{O}$ estado possui uma das maiores jazidas de cassiterita do mundo, responde por $40 \%$ da produção nacional. No segmento industrial, o estado caminha paralelamente com as atividades agrícolas e a extração mineral, estas instalando-se nas proximidades das fontes de matéria-prima (LIMA, 1997).

Os investimentos recentes voltados ao crescimento econômico do estado são as construções de duas grandes usinas hidrelétricas: Jirau e Santo Antônio. A execução de seus projetos foi iniciada em dezembro de 2008 - no principal rio de navegação, o Rio Madeira - 
com a projeção de geração de empregos e movimentação da economia

local nas próximas décadas. As obras deverão impactar igualmente na elevação dos índices econômicos e, consequentemente, estarão vinculadas a outros investimentos, como a fábrica de cimento da Votorantim, que em 2009 entrou em funcionamento em Porto Velho, capital do estado (DECOM, 2010).

O início do desenvolvimento do estado se deu a partir da década de 1970, através do incentivo do governo federal à migração para o estado de Rondônia, estimulando a população excedente principalmente do meio rural, oriunda dos estados das Regiões Sul, Sudeste e Nordeste a migrar para esse território. Grande parte desses migrantes são oriundos, sobretudo, do Nordeste e CentroOeste do País, regiões em que o meio ambiente sofrera igualmente processos de degradação em razão da profunda exploração de seus recursos naturais, de políticas fundiárias centradas na grande propriedade e em difíceis condições sociais e culturais acerca do entendimento da preservação e conservação ambiental.

O principal estímulo oferecido pelo governo federal eram terras a preços bastante acessíveis ou sem custo para povoamento da Região Norte do País (incluindo Rondônia), com infraestrutura para escoar a produção rural e extrativista (LIMA, 1997). O aumento populacional do estado deve-se, principalmente, ao incentivo do fluxo migratório com destino à Rondônia pelo governo federal, para ocupar e desenvolver a região, composto por imigrantes de toda parte do território: paranaenses, paulistas, mineiros, gaúchos, capixabas, mato-grossenses, amazonenses e de vários estados do Nordeste. Este fluxo pode ser acompanhado pela evolução populacional entre as décadas de 1950 e 2010, conforme pode ser verificado na tabela 1 .

Tabela 1 - Evolução populacional em Rondônia por década (1950-2010)

\begin{tabular}{c|c}
\hline Década & População (habitantes) \\
\hline 1950 & 39.935 \\
\hline 1960 & 70.232 \\
\hline 1970 & 111.064 \\
\hline 1980 & 491.069 \\
\hline 1991 & 1.132 .69 \\
\hline 2000 & 1.379 .69 \\
\hline 2010 & 1.560 .501 \\
\hline
\end{tabular}

Fonte: IBGE (2010), Censos Demográficos (1970, 1980, 1980, 1991, 2000 e 2010). 
Os dados populacionais por décadas revelam o intenso crescimento ocorrido entre as décadas de 1970 e 1991, em razão dos incentivos do governo federal à ocupação territorial do estado de Rondônia. Na figura 1, pode ser visualizada a divisão das cinco regiões do Brasil: Norte, Nordeste, Centro-Oeste, Sudeste e Sul.

Figura 1 - As cinco regiões do Brasil e a população gráfica em percentual

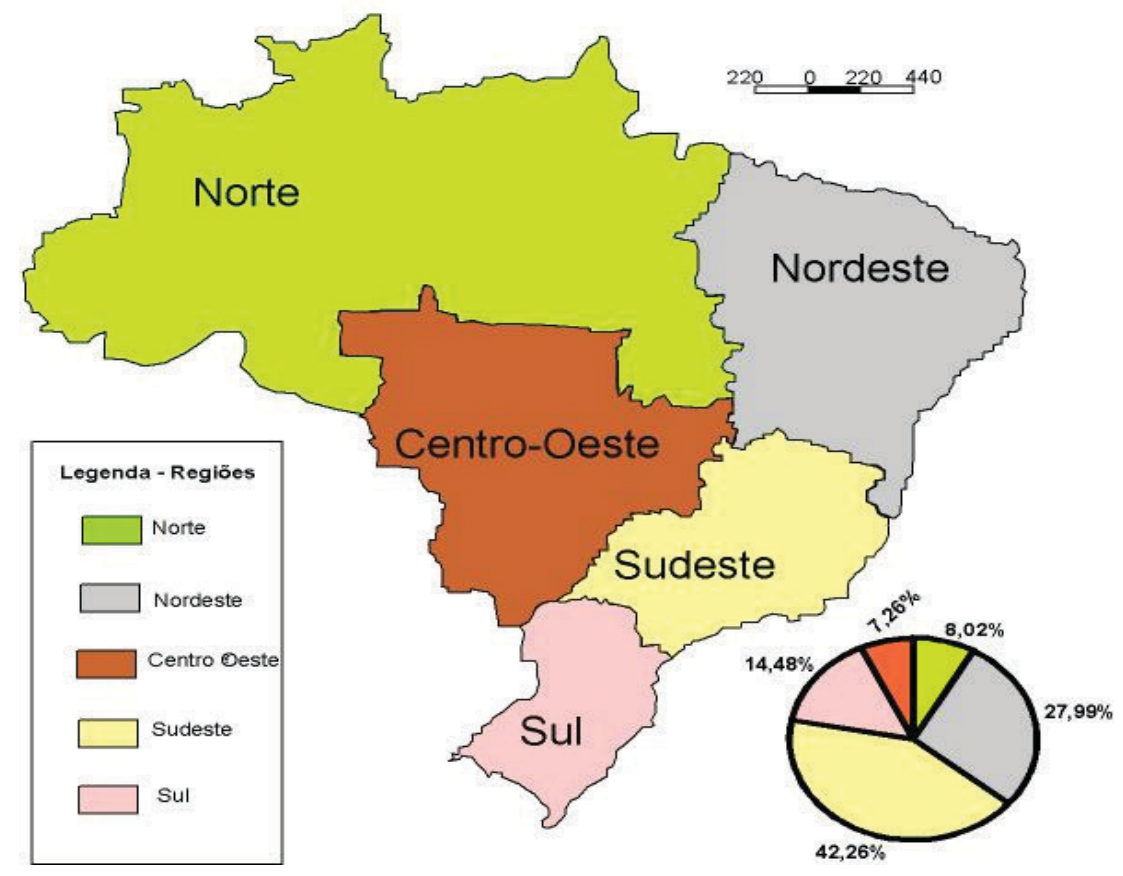

Fonte: adaptada pelos autores, estimativa do IBGE (2010).

Mediante os dados fornecidos pelo IBGE (2010) apresentados na figura 1 , a estimativa do crescimento populacional no Brasil para 2010 apresenta um fato curioso: a Região Norte já não é a menos populosa, com 8,02\%, proporcional às demais regiões. $\mathrm{O}$ menor percentual ficou com a Região Centro-Oeste, com 7,26\%, uma diferença de quase $1 \%$ em relação à Região Norte (IBGE, 2010).

Outra perspectiva de relevância que deve ser observada para o desenvolvimento de uma região são as políticas implementadas pelas diferentes esferas de poder: federal, estadual e municipal. Considerando a necessidade de políticas de desenvolvimento nacionalmente, o governo federal tem implantado projetos visando atender as peculiaridades distintas, com programas 
de desenvolvimento para abranger todo o território. Em 2003, início do Governo Lula, foi implementada a Política Nacional de Desenvolvimento Regional (PNDR), por meio do Ministério da Integração Nacional. A PNDR tinha como propósito reduzir as desigualdades regionais e ativar as potencialidades de desenvolvimento das regiões brasileiras, explorando a imensa e fantástica diversidade que se observa no nosso país de dimensões continentais. A PNDR organiza as ações e os programas implementados, para que sejam regulados a partir de um referencial nacional comum capaz de produzir os efeitos desejados na redução das desigualdades regionais. Trata-se de iniciativas pioneiras de desenvolvimento integrado e sustentável, em que podem ser citados os Arranjos Produtivos Locais (APLs) que se desenvolvem nas diferentes mesorregiões. Essas ações foram desencadeadas após a aprovação da PNDR em 2004, e suas diretrizes são seguidas pelas políticas setoriais dos diferentes ministérios do Governo Federal. Todas as propostas foram organizadas com o aval da sociedade regional, a partir de um amplo processo de participação e consulta local que resultou em ações como o Plano Amazônia Sustentável (PAS), o Plano de Desenvolvimento Sustentável do Nordeste (PNDE), o Plano Estratégico de Desenvolvimento do CentroOeste e os planos específicos de desenvolvimento sustentável para os vales do Jequitinhonha e do Mucuri, o Plano Estratégico de Desenvolvimento do Semi-Árido (PDSA) e o Plano de Desenvolvimento Integrado e Sustentável da Mesorregião dos Vales do Jequitinhonha e do Mucuri. No mesmo período, o governo federal implantou o PTDRS, que tinha como objetivo o desenvolvimento rural e a diminuição da pobreza, plano que descreveremos na sequência.

O setor mais carente de políticas de desenvolvimento na região em estudo é o rural. De acordo com Assis (2006), o desenvolvimento rural sustentado deve ser implementado em base local e regional, porque é nessas instâncias que se pode contrapor alguma espécie de controle social legitimamente instituído à capacidade de influência do grande capital. Em função disso, essa implementação deve ocorrer através de políticas públicas que facilitem a organização e ações de toda a sociedade. Política pública aqui é entendida como aquela que designa o "Estado em ação"; é o "Estado implantando um projeto de governo, através de programas, de ações voltadas para setores específicos da sociedade" (HÖFLING, 2001, p. 1). 
O Brasil apresenta grande extensão territorial; considerando os valores das áreas territoriais, de acordo com a estrutura políticoadministrativa, assim como as demais alterações territoriais decorrentes no período, utilizando como referência o censo demográfico realizado pelo IBGE em 2010, a superfície do Brasil totaliza uma extensão geográfica de $8.515 .767,049 \mathrm{~km}^{2}$ (IBGE, 2010).

Devido a essa ampla estrutura geográfica, as diversidades socioculturais e ambientais entre suas regiões se diferenciam dentro do mesmo estado. A Região Norte, em particular, apresenta características peculiares e necessidades muito diferenciadas das demais regiões, com processos de ocupação territorial muito recentes, o que justifica a necessidade de estudo e políticas específicas de desenvolvimento para a região.

\section{Território rural e sustentabilidade}

Os espaços rurais no Brasil constituem-se em realidades complexas e com especificidades que particularizam as dinâmicas regionais em que se inserem. A ruralidade presente nesses espaços exige que as políticas públicas levem em conta a geração de emprego, o aumento do nível de renda e a melhoria das condições de vida e de trabalho das populações neles existentes (MONTEIRO, 2006). Desse modo, as políticas de governo voltadas à sustentabilidade de territórios significam uma orientação das ações públicas motivada pelo reconhecimento da limitação ecológica fundamental dos recursos (CAVALCANTI, 2001).

O território pode ser caracterizado como um espaço que sintetiza e materializa, num determinado espaço geográfico, um processo social, econômico, ecológico e cultural complexo, em interação com outros espaços diferenciados. O território não se limita a uma simples demarcação geográfica ou políticoadministrativa, traçada de forma mais ou menos arbitrária ou como reflexo de interesses políticos, mas só existe como articulação e relação com outros espaços ou formações socioculturais (BUARQUE, 1997).

Segundo Duncan e Guimarães (2003), o enfoque territorial refere-se a um determinado espaço - não necessariamente contínuo - e a uma determinada concentração de população, em que se examinam as unidades ambientais, os recursos naturais, as 
atividades econômicas, as infraestruturas econômica e social, as relações sociais, os domínios institucionais e os limites políticos.

O território rural é um espaço composto pelos recursos naturais, de produção diversificada, que não deve ser confundida com produção agrícola. Restringir o rural ao agrícola é voltar ao tempo em que as atividades agrícolas eram vistas somente no meio rural. Segundo Brose (2001), a agricultura é apenas um dos elementos constituintes do meio rural, à medida que é composto por fatores sociais (educação, religião, lazer, entre outros), econômicos (fontes de renda não agrícola, como o turismo, comércio, manufaturas), políticos e outros (MDA, 2005).

O PTDRS parece apontar uma proposta de desenvolvimento rural sustentável em seu objetivo, visto que visa considerar as peculiaridades locais e regionais, e as reivindicações feitas ao longo de várias décadas, no sentido da construção de uma política pública coletiva e participativa do poder público e da sociedade civil, permitindo não somente a descentralização de projetos, mas também a maximização dos recursos (MDA, 2005).

De fato, no Brasil, a discussão sobre desenvolvimento sustentável tem ganhado força nos últimos dez anos e mostrase cada vez mais uma prerrogativa de esferas governamentais, empresas e demais organizações com diferentes finalidades. $\mathrm{O}$ posicionamento presente no PTDRS, de discutir as práticas que se apoiam na ideia de sustentabilidade, baseia-se no discurso de sustentabilidade desde as estratégias de sua elaboração até os resultados obtidos (MDA, 2005). No entanto, ainda não se tem uma avaliação precisa dos reais impactos, dentro de uma perspectiva regional, das ações implementadas por tais programas federais, considerando a sua recente implantação e a difícil articulação da esfera federal com os atores locais e regionais, em razão da forte centralização das políticas públicas brasileiras.

\section{Implementação e gestão do PTDRS}

A implementação do PTDRS iniciou em 2003, durante a primeira gestão do governo Lula, e visava estabelecer um processo de discussão de uma proposta de trabalho a ser implementada pela nova Secretaria de Desenvolvimento Territorial (SDT) do MDA. De fato, a sua concepção básica foi fruto do período de transição entre dois governos - Fernando Henrique Cardoso e Lula. Esse documento buscou dar consistência a um acúmulo 
de conhecimentos que estavam sendo gerados por cientistas, entidades públicas e não governamentais que, de uma ou outra forma, desenvolviam análises e projetos na direção apontada pelo mesmo. Ele tornou-se base para a formulação do programa de desenvolvimento sustentável dos territórios rurais, incluído como tal no PPA 2004-2007, e hoje operado como um conjunto de conceitos e propostas pela SDT.

O plano tem como pressuposto o desenvolvimento integral do território, que deve integrar uma visão ampla, projetando todas as ações necessárias ao seu processo de desenvolvimento sustentável, independentemente das fontes de financiamento ou parcerias a serem formadas, sejam elas de natureza pública ou privada, dentro ou fora do espaço territorial. Caracteriza-se como um instrumento auxiliar de gestão social que permite aos atores sociais negociar técnica e politicamente com todas as instâncias a viabilização das ações projetadas. No sentido de orientar os participantes do processo, foi confeccionado um guia de planejamento e gestão do PTDRS (MDA, 2005). O documento expressa a formulação do plano como um processo, cujas etapas guardam uma coerência e uma sequência lógica: i) marco conceitual-metodológico; ii) caracterização dos beneficiários; iii) conhecimento crítico da realidade (diagnóstico); iv) identificação dos eixos de desenvolvimento (diretrizes globais); v) orientações ao detalhamento das propostas (as linhas de ação e projetos específicos) (MDA, 2005).

Diante das etapas em execução do PTDRS, o plano pode ser avaliado como parte das ações do Programa Território da Cidadania (PTC), pois este envolve a participação da população rural local, apresentando suas necessidades peculiares à região.

\section{Políticas Públicas: Programa Territórios da Cidadania}

A decisão do governo brasileiro em propor uma política nacional que apoiasse o desenvolvimento sustentável dos territórios rurais foi resultado de um processo de acúmulos e de reivindicações de setores públicos e organizações da sociedade civil, que avaliaram como necessária a articulação de políticas nacionais com iniciativas locais (MDA, 2005).

Trata-se de uma estratégia de desenvolvimento e de gestão de políticas públicas a partir do estímulo de reconhecimento ou de criação de territórios de identidade rural, e tem por objetivo 
promover a inclusão social e o exercício da cidadania no meio rural (RIOTERRA, 2010). A proposta do Programa Territórios da Cidadania (PTC) é o desenvolvimento territorial sustentável considerando as peculiaridades locais e regionais, e as reivindicações feitas ao longo de várias décadas, no sentido da construção de uma política pública coletiva e participativa do poder público e da sociedade civil, permitindo não somente a descentralização de projetos, mas também a maximização dos recursos (RIOTERRA, 2010).

Segundo esta política do governo federal, o Brasil encontrou o caminho para o crescimento econômico com a redução das desigualdades sociais e regionais. O desafio é construir a cidadania, ou seja, a melhoria da renda e da qualidade de vida a todos os brasileiros, especialmente no meio rural, onde ainda residem as maiores desigualdades. O Territórios da Cidadania é um programa de desenvolvimento regional sustentável que visa à garantia de direitos sociais voltados às regiões mais vulneráveis do País, com objetivo de estimular o desenvolvimento econômico e universalizar os programas básicos de cidadania. Tomando como base a integração das ações do governo federal e dos governos estaduais e municipais, conduz suas ações através de um plano desenvolvido em cada território, com a participação da sociedade. Visando à demarcação dos territórios rurais, definiram-se conjuntos de municípios integrados pelas mesmas características econômicas e ambientais que mantenham identidade e coesão social, cultural e geográfica. Maiores que o município e menores que o estado, os territórios são recortes estabelecidos como critério de demonstração das diferenças existentes na realidade dos grupos sociais, das atividades econômicas e das instituições de cada localidade, o que facilita o planejamento de ações governamentais para o desenvolvimento dessas regiões (MDA, 2005).

Para fazer parte do Programa Território da Cidadania, os municípios precisam participar de um Plano de Desenvolvimento Territorial, como o PTDRS. Um território rural se define por sua identidade social, econômica e cultural através dos seguintes requisitos: Conjunto de municípios com até 50 mil habitantes; Densidade populacional menor que 80 habitantes $/ \mathrm{Km}^{2}$; Organizados em territórios rurais de identidade; Integrados com os Consórcios de Segurança Alimentar e Desenvolvimento Local (CONSAD), do Ministério do Desenvolvimento Social (MDS) 
e/ou Mesorregiões, do Ministério da Integração Nacional (MI). Para identificação de quais territórios seriam o foco da atuação do Programa Territórios da Cidadania, foram definidos os seguintes critérios técnicos: menor IDH; maior concentração de agricultores familiares e assentamentos da Reforma Agrária; maior concentração de populações quilombolas e indígenas; maior número de beneficiários do Programa Bolsa Família; maior número de municípios com baixo dinamismo econômico; e maior organização social (MDA, 2005).

$\mathrm{Na}$ implantação do PTC, em 2008, o governo federal, para atender todo o território nacional, inicia sua implantação em 60 territórios. Nesse primeiro momento, foram atendidos os territórios rurais de baixo Índice de Desenvolvimento Humano (IDH), abrangendo cerca de 958 municípios em todos os estados da Federação, divididos em cinco regiões, como expressa a tabela 2 .

Tabela 2 - Quantidade de territórios rurais segundo regióes e estados

\begin{tabular}{l|c|c|c}
\hline Região & No de estados & No de municípios & $\begin{array}{c}\text { No territórios } \\
\text { rurais (PTC) }\end{array}$ \\
\hline Norte & $\begin{array}{c}05+02 \\
\text { (territórios) }\end{array}$ & 130 & 13 \\
\hline Nordeste & 09 & 499 & 29 \\
\hline $\begin{array}{l}\text { Centro- } \\
\text { Oeste }\end{array}$ & $\begin{array}{c}03+\text { Distrito } \\
\text { Federal }\end{array}$ & 81 & $05+01(\mathrm{DF})$ \\
\hline Sudeste & 04 & 167 & 08 \\
\hline Sul & 03 & 81 & 04 \\
\hline Total & $\mathbf{2 7}$ & $\mathbf{9 5 8}$ & $\mathbf{6 0}$ \\
\hline
\end{tabular}

Fonte: adaptado pelos autores, Território da Cidadania (MDA, 2008).

A tabela 2 apresenta o quantitativo dos estados, municípios e números dos territórios rurais que compuseram os primeiros 60 territórios implementados pelo Governo Federal por meio do Programa Território da Cidadania. Esse foi composto de 27 estados, incluindo o Distrito Federal e os dois territórios (Amapá e Roraima), apresentando as características pré-estabelecidas pelo Programa: Municípios: 958 (17\% do total de municípios); População Total: 24 milhões (14\%); População Rural: 7,8 milhões (27\%); Agricultura Familiar: 1 milhão de agricultores (24\%); Assentados Reforma Agrária: 319,4 mil famílias (40\%); Bolsa Família: 2,3 milhões de famílias (21\%); Comunidades 
Quilombolas: 350 (37\%); Terras Indígenas: 149 (25\%); Pescadores: 127,1 mil (33\%) (MDA, 2008).

A regionalização do PTC para a Região Norte do País, no primeiro momento, foi implantada em 13 estados, conforme pode ser verificado na tabela 3 , a seguir.

Tabela 3 - Regionalização do Programa Territórios da Cidadania (Região Norte)

\begin{tabular}{c|l|l}
\hline N. & Estados & Territórios \\
\hline 1 & Acre (AC) & Alto Acre e Capixaba \\
\hline 2 & Rondônia (RO) & Central (Ji-Paraná) \\
\hline 3 & Roraima (RR) & Sul de Roraima \\
\hline 4 & Amazonas (AM) & Alto Rio Negro \\
\hline 5 & Amazonas (AM) & Entorno de Manaus \\
\hline 6 & Amazonas (AM) & Baixo Amazonas \\
\hline 7 & Pará (PA) & Baixo Amazonas \\
\hline 8 & Pará (PA) & Transamazônica \\
\hline 9 & Pará (PA) & Sudeste Paraense \\
\hline 10 & Pará (PA) & Nordeste Paraense \\
\hline 11 & Pará (PA) & Marajó \\
\hline 12 & Amapá (AP) & Sul do Amapá \\
\hline 13 & Tocantins (TO) & Bico do Papagaio
\end{tabular}

Fonte: adaptada pelos autores, dados do Território da Cidadania (MDA, 2008).

De acordo com a política de estruturação para a implantação do PTC, alguns estados, na ocasião, foram beneficiados com mais de um recorte territorial rural, de acordo com sua extensão e com os níveis de complexidade regional identificados pelo governo federal. Assim, observa-se na tabela 3 a maior concentração de territórios vinculados ao PTC nos dois maiores estados da região, Amazonas e Pará.

$\mathrm{Na}$ figura 2, pode ser visualizada a localização dos Territórios da Cidadania implantados em 2008, pelo governo federal, na Região Norte. Observa-se, ainda, a espacialização desses territórios na referida região. 

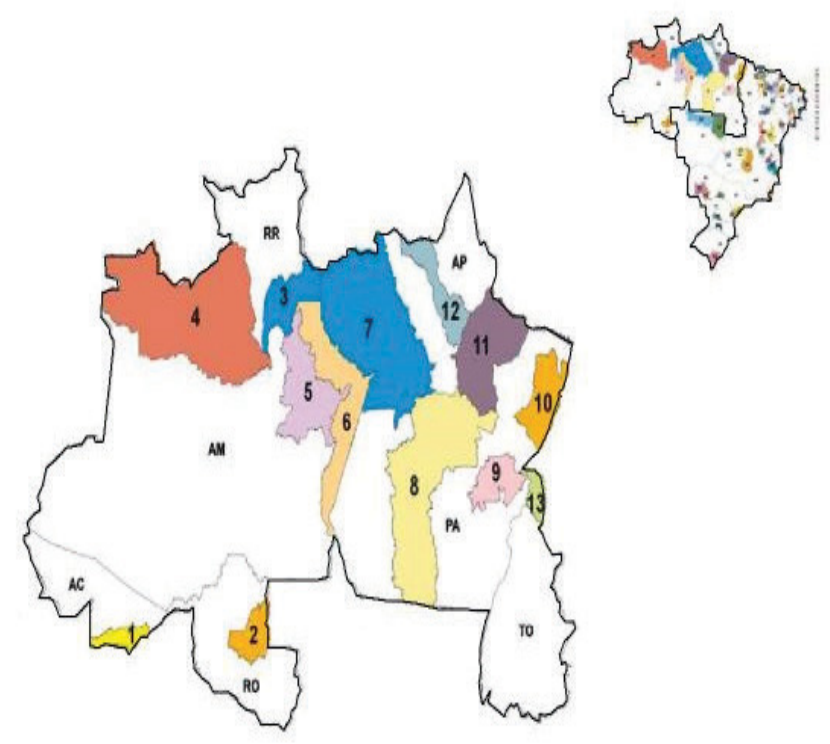

Fonte: adaptada pelos autores, dados do Programa Territórios da Cidadania (MDA, 2008).

A constituição dos territórios da cidadania é definida pelos projetos aprovados pelo MDA, obedecendo às predefinições do PTC implementado pelo governo federal.

No primeiro momento de implementação do PTC em âmbito nacional, no estado de Rondônia foi implementado somente um Território da Cidadania, o de n. 2, denominado como Território Central, conforme figura apresentada anteriormente. No entanto, no decorrer de 2008, foram homologados mais dois PTCs no estado, que passou a contar assim com três grandes recortes territoriais para o desenvolvimento rural, os quais se destacam: Território Madeira Mamoré, Território Vale do Jamari e Território Central. $\mathrm{Na}$ ocasião, também estavam em fase de elaboração e aprovação pelo STA/MDA mais dois projetos do PTDRS, desenvolvidos para outros PTCs no estado: Rio Machado e Vale do Guaporé.

$\mathrm{Na}$ consolidação do PTDRS em Rondônia, foram realizadas mobilizações pelo Fórum de Implementação das Ações do 
Território Central de Rondônia - FIATEC. Dentre um de seus produtos, o FIATEC, em parceria com o Grupo de Pesquisa e Extensão em Sistemas Agroflorestais do Acre (PESACRE) e outras entidades, efetivou o Plano Territorial de Desenvolvimento Rural Sustentável (PTDRS) do Território Central de Rondônia (MDA, 2007). A figura 3 apresenta os recortes dos três territórios rurais na divisão geográfica do estado de Rondônia, para a implementação dos PTCs.

Figura 3 - Localização dos Territórios rurais em Rondônia

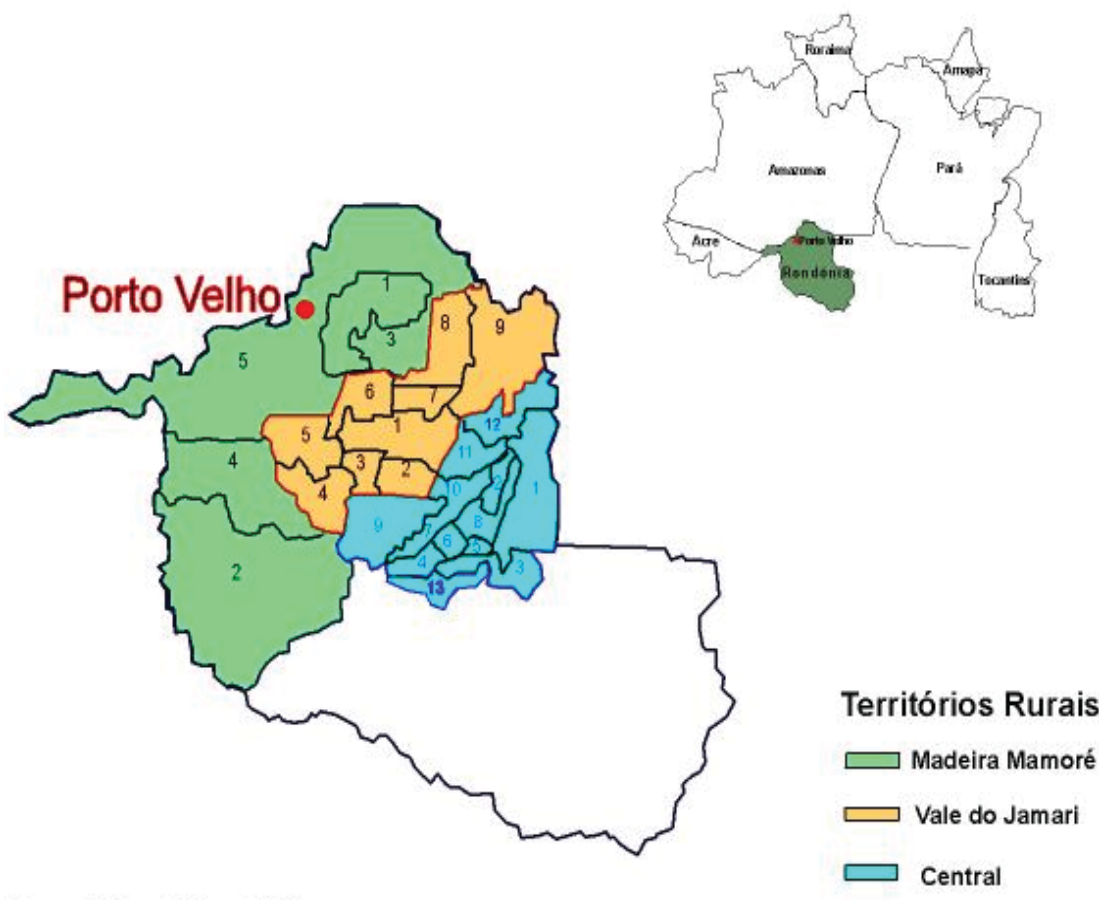

\begin{tabular}{l}
0 \\
$50 \quad 100 \quad 150$ \\
\hline
\end{tabular}

Fonte: adaptada pelos autores, dados do MDA/SDT (2008).

Observa-se que os três territórios homologados em 2008 pelo MDA no Programa Territórios da Cidadania são ligados um ao outro, sendo o mais antigo o Central, de cor azul, seguindo o Vale do Jamari, de cor marrom claro, e o Madeira Mamoré, de cor verde - este, com apenas cinco municípios, dentre eles a capital, Porto Velho. Na sequência, realiza-se uma breve descrição da composição e características de cada território:

Território Central - compreendido por treze municípios: Alvorada do Oeste, Ji-Paraná, Jarú, Ouro Preto do Oeste, Presidente Médici, Vale do Paraíso, Urupá, Mirante da Serra, 

e Vale do Anari. Segundo o zoneamento socioeconômicoecológico do Estado (ZSEE/RO), agrupados pelas mesmas características e definidos na zona 1 em áreas propícias a exploração e uso da terra, principalmente agropecuária, com grau variável de ocupação, vulnerabilidade ambiental e outras aptidões de uso como a agroflorestal (SEPLAN, 2006);

Vale do Jamari - compreendido por nove municípios: Alto Paraíso, Ariquemes, Buritis, Cacaulândia, Campo Novo de Rondônia, Cujubim, Machadinho D’Oeste, Monte Negro e Rio Crespo. Esses municípios se caracterizam como área de exploração à produção e ao uso da terra. Destes nove municípios, oito estão localizados na zona 1 do ZSEE/RO, somente o município de Buritis está na zona 2 do zoneamento, o qual tem seu uso de exploração limitado ao manejo e à preservação (SEPLAN, 2006);

Madeira Mamoré - compreende apenas cinco municípios: Candeias do Jamarí, Porto Velho, Itapoã do Oeste, GuajaráMirim e Nova Mamoré. Segundo o ZSEE/RO, suas áreas estão localizados nas zonas 2 e 3 do zoneamento, de uso restrito, passíveis ao manejo sustentável e controlado pelas Unidades de Conservação Ambiental e Reserva Indígena, instituídas pela União, estados e municípios (SEPLAN, 2006). Dentre esses cinco municípios está Porto Velho, a capital do estado, que tem perspectivas mais centradas aos grandes investimentos.

Dos três territórios rurais implementados pelo governo federal até 2010, foram escolhidos para o estudo dois, por pertencerem ao mesmo estado, estarem localizados na mesma região geográfica e apresentarem características, necessidades e potencialidades muito distintas entre si: o Território Central e o Madeira Mamoré. O Território Central foi o primeiro a ser reconhecido e receber mais investimento nas áreas rurais pelo PTC. $\mathrm{Na}$ época de sua implementação, era o que estava mais consolidado. Na figura 4, estão identificados os municípios do Território Central contemplados pelo PTDRS e pelo Programa dos Territórios da Cidadania. 
Figura 4 - Identificação dos municípios no Território Central/RO

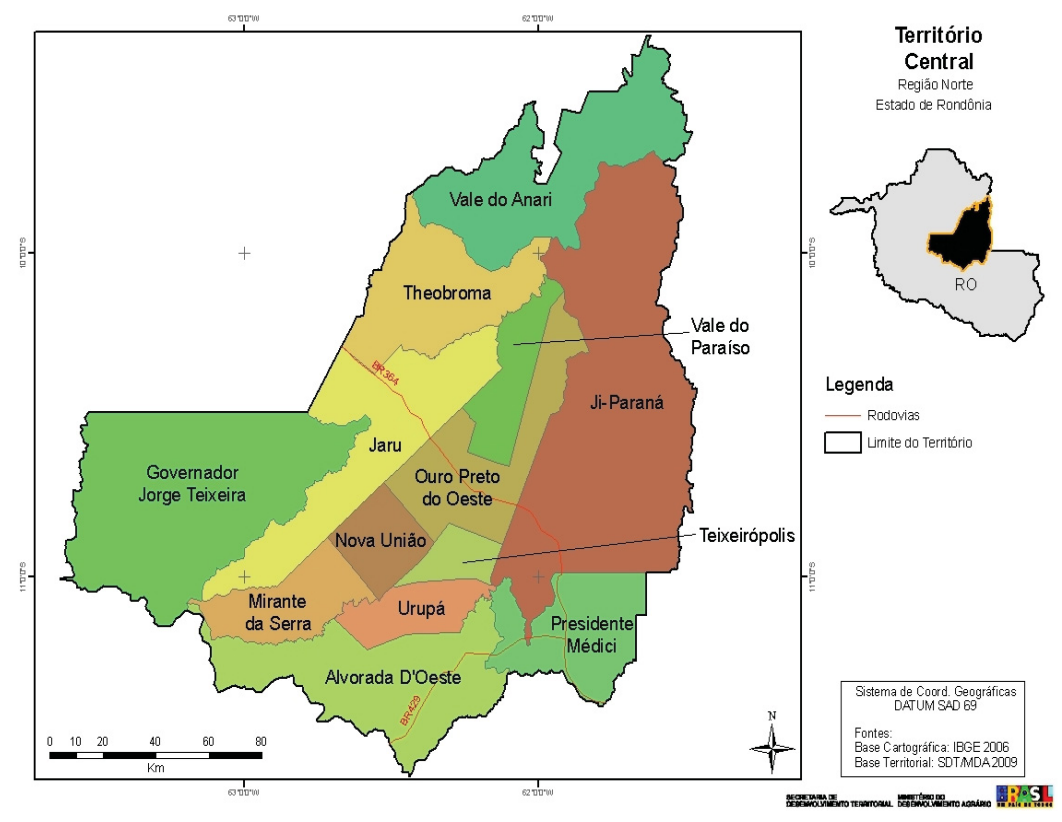

Fonte: Base Cartográfica IBGE (2006), MDA/SDT (2008).

Observando a figura 4, verifica-se que no Território Central destacam-se em extensão os municípios de Governador Jorge Teixeira e de Ji-Paraná. O município de suporte ao Território Central é Ji-Paraná, considerado o mais desenvolvido economicamente e, depois da capital (Porto Velho), o mais populoso do estado.

À época da implantação do PTDRS, em 2003, a região do Território Central já dispunha de certo capital social e articulação entre seus atores sociais. A região já contava com ações do próambiente e de fóruns e planos de desenvolvimento locais. Isto, em parte, contribuiu e até mesmo facilitou o entendimento e absorção da proposta de desenvolvimento territorial pelos gestores da região (MDA, 2007). O PTDRS é expandido de forma participativa, por diferentes atores sociais, tais como técnicos, gestores do governo e sociedade civil organizada.

No Território Central, estão localizados 24 Projetos de Assentamento da Reforma Agrária (P.A.), com mais de 4.300 famílias beneficiadas. Em seu espaço geopolítico, estão localizadas cinco Unidades de Conservação: Reserva Biológica Jarú (nos municípios de Vale do Anari e Ji-Paraná); Parque Nacional do Pacaás Novos (no município de Governador Jorge Teixeira); Parque Municipal Chico Mendes (no município de Ouro Preto do Oeste); Reservas Extrativistas Aquariquara e Itaúba (no 
município de Vale do Anari).Também estão presentes duas Terras Indígenas: T.I. Igarapé Lurdes (no município de Ji-Paraná) e T.I. Uru-Eu-Wau-Wau (no município de Governador Jorge Teixeira). De um modo geral, estas áreas protegidas encontram-se bastante ameaçadas por ações de depredação: roubo de madeira, caça e pesca ilegal, e grilagem de terras (SEPLAM, 2006).

O outro território em questão é o Território Madeira Mamoré, pelos interesses divergentes: os da capital, Porto Velho, centrados aos grandes investimentos econômicos, tanto públicos como privados, à implementação de políticas públicas, especialmente em indústrias e obras de grande porte, por exemplo, as usinas hidrelétricas do Rio Madeira: Jirau e Santo Antônio; e os dos municípios: Candeias do Jamari, Itapoã do Oeste, Nova Mamoré e Guajará-Mirim, este com características e necessidades diferenciadas, principalmente no que se refere a políticas voltadas aos pequenos produtores. A população desses municípios é composta por ribeirinhos, seringueiros e assentados da reforma agrária, com projetos de desenvolvimento limitados às características definidas pelo ZSEE/RO.

A figura 5 apresenta a localização do Território Madeira Mamoré em Rondônia e, respectivamente, os cinco municípios que integram esse território.

Figura 5 - Identificação do Território Madeira Mamoré/RO

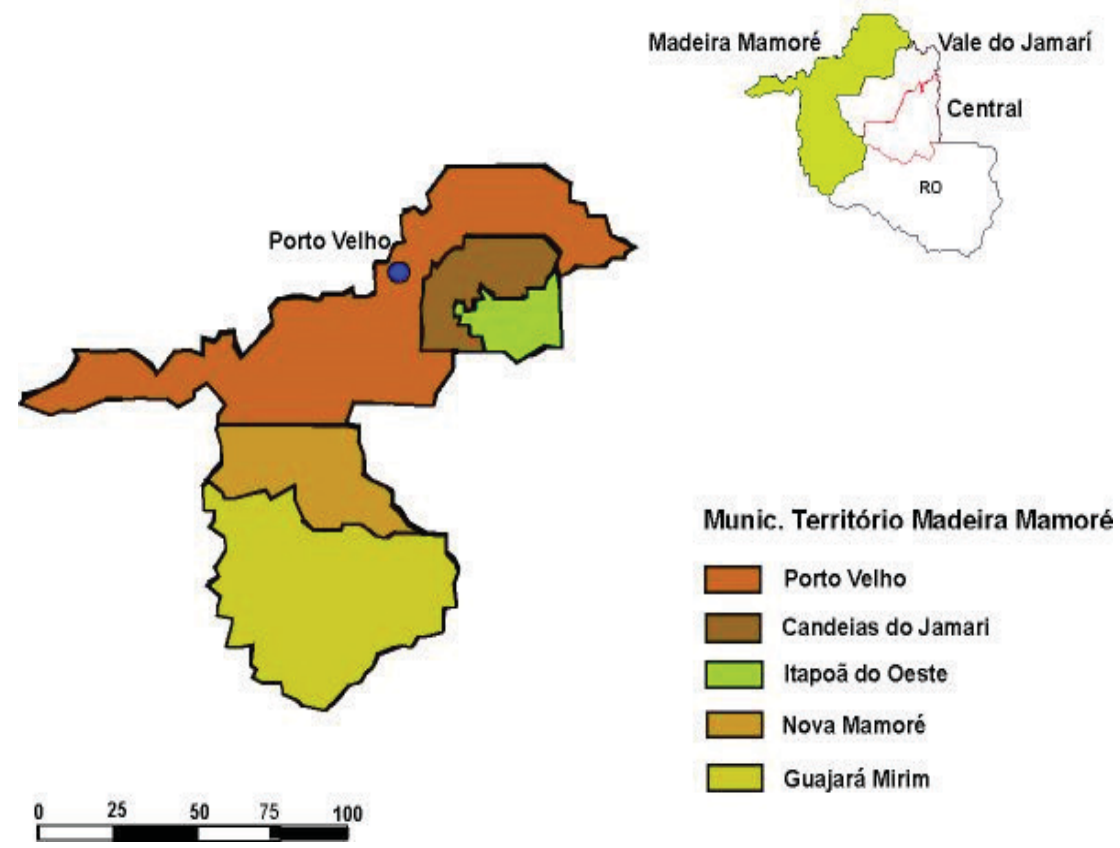

Fonte: adaptada pelas autoras, dados do MDA/STD (2008). 
O PTC Madeira Mamoré é um território com poucos municípios mais extensos. As políticas de implementação desse território tiveram início em 2004, seguindo as mesmas linhas dos demais territórios rurais implantados em outras regiões brasileiras.

Os cinco municípios que fazem parte do Território Madeira Mamoré podem ser identificados na figura 5, onde se observa a localização da capital do estado Porto Velho no recorte do município. O PTC Madeira Mamoré tem como principal objetivo contribuir para a construção de um novo modelo de desenvolvimento para a região, considerando questões como a valorização da floresta e o respeito às populações tradicionais. Uma das estratégias é fortalecer a sociedade civil organizada no referido território. Para tanto, busca-se promover um maior envolvimento popular nos processos de formulação e implementação de políticas públicas, especialmente nas obras das usinas hidrelétricas do Rio Madeira (WWF BRASIL, 2008).

Diante dos programas e planos existentes, observa-se um interesse por parte do governo federal em investir na ocupação da Região Norte. No entanto, as profundas diferenças territoriais existentes e interesses diversificados contrapõem práticas muito tradicionais e particulares da região a investimentos internacionais. Estas diferenças são de difícil convergência, o que torna o papel do Estado brasileiro uma condição necessária para o reconhecimento dos valores ali existentes e para a verificação de possibilidades de negociação na organização territorial.

\section{Considerações finais}

Com base nas referências bibliográficas pesquisadas e mediante a coleta de dados em órgãos e repartições públicas, foi possível apresentar os três recortes territoriais, pertinentes ao estado de Rondônia, um dos treze estados situados na Região Norte do Brasil que participam do PTDRS desde 2003 e do Programa Territórios da Cidadania desde 2008. O estudo mostrou as principais transformações populacionais de Rondônia desde 1950 até 2009 (estimativa), em dados fornecidos pelo IBGE (2010), pontuados por aspectos históricos que contextualizam as diferenças de desenvolvimento territorial em diferentes momentos de sua história.

Diante da breve descrição histórica do estado, foi possível mostrar as diferentes características da região e as necessidades 
Considerando-se as bases do PTDRS para o desenvolvimento sustentável, buscou-se, através de análise do PTC, que tem como objetivo a implementação de diretrizes estratégicas das políticas de territorialização de Rondônia, identificar algumas das ações realizadas a partir do PTDRS nos dois territórios citados.

Considera-se que o processo de desenvolvimento do estado de Rondônia requer políticas públicas específicas devido às diversidades existentes na região e em todo o País. A necessidade de políticas públicas específicas também se fundamenta na visão de que o que é sustentável em um local, período de tempo ou certo estágio de desenvolvimento pode não ser sustentável em outro (CAMPANHOLA; GRAZIANO, 2000).

Para Wanderley (2001, p. 31), essas políticas devem se preocupar com a recuperação do potencial de terras e recursos naturais disponíveis, com a valorização do patrimônio natural e cultural do meio rural, favorecer mais os povos tradicionais e considerar o devido valor da agricultura familiar e as formas alternativas de produção.

Por fim, destaca-se a necessidade de relacionar a gestão política ao desenvolvimento sustentável do estado, considerando os planos e programas do governo como condição prioritária para garantir o bem-estar, bem como a produção agrícola e agropecuária e a permanência do homem no campo, contribuindo assim com políticas públicas para o desenvolvimento local.

\section{Referências}

ADIB, Alberto Renault. Plano Territorial de Desenvolvimento Rural Sustentável. Guia para o planejamento. IICA Brasil. Brasília, 2005. Disponível em: <www.iica.int/.../Plano\%20territorial\%20desenvolvimento\%20rural>. Acesso em: 5 jul. 2010.

ASSIS, Renato L. de. Desenvolvimento rural sustentável no Brasil: perspectivas a partir da integração de ações públicas e privadas com base na agroecologia. Economia Aplicada, v. 10, n. 1, p. 75-89, jan.-mar. 2006.

CAMPANHOLA, Clayton; GRAZIANO DA SILVA, José. Desenvolvimento local e a democratização dos espaços rurais. Cadernos de Ciência \& Tecnologia, Brasília, v. 17, n. 1, p. 11-40, jan./abr. 2000.

CAVALCANTI, Clóvis. Política de governo para o desenvolvimento sustentável: uma introdução ao tema e a esta obra coletiva. In: CAVAL- 
CANTI, Clóvis (Org.). Meio ambiente, desenvolvimento sustentável e políticas públicas. 3. ed. São Paulo: Cortez, 2001. p. 21-40.

DECOM - Departamento de Comunicação Social. Crescimento da economia de Rondônia. Disponível em: <www.rondonia.ro.gov.br/noticias.asp>. Acesso em: 23 jun. 2010.

FIATEC - Plano Territorial de Desenvolvimento Rural Sustentado do Território Central do Estado de Rondônia. FIATEC/PEACRE, out. 2007.

HÖFLING, Eloisa de M. Estado e políticas (públicas) sociais. Cadernos CEDES, Campinas, v. 21, n. 55, p. 30-41, 2001.

IBGE - Instituto Brasileiro de Geografia e Estatística. Demografia do Brasil. Similares. 2010. Disponível em: <www.ibge.gov.br/home/geociencias/areaterritorial/principal>. Acesso em: 10 set. 2010.

LIMA, Abnael Machado de. Terras de Rondônia: aspectos físicos e humanos do Estado de Rondônia. Porto Velho: Off-7, 1997.

MDA - Ministério do Desenvolvimento Agrário. Plano Territorial de Desenvolvimento Rural Sustentável: guia para o planejamento. Documento de Apoio No 02. Brasília, nov. 2005. Disponível em: <http://sistemas.mda.gov.br/sdt/pdf $>$. Acesso em: 21 fev. 2010.

Programa Nacional de Desenvolvimento Sustentável de Territórios Rurais: referência para o apoio ao desenvolvimento territorial. Brasília, 2004. Mimeo.

Referências para uma Estratégia de Desenvolvimento Rural Sustentável no Brasil. Mar. 2005. Disponível em: <http://sistemas. mda.gov.br/sdt/arquivos/0749311385.pdf>. Acesso em: 21 fev. 2010.

Referências para a gestão social de territórios rurais. 2005. Disponível em: <www.mda.gov.br/sdt/index>. Acesso em: 5 jul. 2010.

Secretaria de Desenvolvimento Territorial - SDT. Territórios da Cidadania: Concepção e gerenciamento. 2008. Disponível em: <www. cultura.gov.br/site/wp-content/uploads/2008/02/1574015804-1.pdf>. Acesso em: 5 set. 2010.

Território Central - Estado de Rondônia: Plano Territorial De Desenvolvimento Rural Sustentado. Out. 2007. Disponível em: <www.mda.gov.br/sdt/index >. Acesso em: 5 jul. 2010.

MIN - Ministério da Integração Nacional. Política Nacional de Desenvolvimento Regional do Brasil: a redução das desigualdades regionais é um dos objetivos fundamentais da República. Disponível em: <www.ec.europa.eu/regionalpolicy/international/pdf/pndrbrasil.pdf>. Acesso em: 10 fev. 2011. 
MONTEIRO, Rosa C. Novas ruralidades e políticas públicas: proposições para um debate. In: FROEHLICH, José M.; DIESEL, Vivien (Orgs.). Desenvolvimento rural: tendências e debates contemporâneos. Ijuí: Unijuí, 2006. p. 155-174.

RIOTERRA - Centro de Estudos da Cultura e do Meio Ambiente da Amazônia. Territórios Rurais Madeira Mamoré. Disponível em: <www.rioterra.org.br/file=editais >. Acesso em: 5 jul. 2010.

SEPLAN - SECRETARIA DE PLANEJAMENTO - Lei Complemen$\operatorname{tar}$ No 233, de 06 de Junho de 2000 - Dispõe sobre o Zoneamento Socioeconômico-Ecológico do Estado de Rondônia - ZSEE. 2006. Disponível em: <www.seplan.ro.gov.br/conteudo.asp>. Acesso em: 19 out. 2009.

WANDERLEY, Maria de N. B. A ruralidade no Brasil moderno. Por um pacto social pelo desenvolvimento rural. Red de Bibliotecas Virtuales de Ciencias Sociales de América Latina y el Caribe de CLACSO. 2001. p. 31-44. Disponível em: <http://bibliotecavirtual.clacso.org.ar/ ar/libros/rural>. Acesso em: 10 fev. 2009.

WWF Brasil. Um novo modelo de gestão territorial para Rondônia. Jul. 2008. Disponível em: <www.wwf.org.br/index.cfm?uNews>. Acesso em: 12 jul. 2010.

\title{
IMPLEMENTATION PLAN SUSTAINABLE TERRITORIAL RURAL DEVELOPMENT PROGRAMME AND TERRITORIES OF CITIZENSHIP IN THE STATE OF RONDÔNIA
}

\begin{abstract}
This article discusses interventions aimed at territorial development in Brazil, by the policies of local/ rural development and more specifically the Territorial Plan for Sustainable Rural Development (PTDRS) in the State of Rondônia. This policy, implemented at the beginning of the Lula Government (2003), focused on two territorial cuts in Rondonia: the Central and Madeira Mamore, in that the first two were to participate in the State Plan. The article is structured in two phases: in the first, we analyze the main results of the survey in migration to the occupation and development of the State of Rondônia between 1950 and 2010. The second reflected on the deployment of Territories of Citizenship Program in both territorial clippings Rondônia. Using the procedures of analysis of statistical data available in official bodies and documentary research - provided by the Ministry of Agrarian Development (MDA) - about concepts and evaluations of rural policies in the country. Part is the hypothesis that in Brazil, the central condition of rural public policies implemented by the federal government shortly consider the spatial, social and economically differentiated regional characteristics.
\end{abstract}

Keywords: Territory. Rural Development. Public Policy. Northern Region of Brazil. 